\title{
Information technologies implementation for reducing water losses in water supply systems
}

\author{
Dmitry Serov ${ }^{1, *}$ \\ ${ }^{1}$ Peter the Great St. Petersburg Polytechnic University, 195251, Polytechnicheskaya Street, 29, \\ St. Petersburg, Russia
}

\begin{abstract}
The article discusses the elements of an automated system for collecting, storing and transmitting data on water consumption, modern metering devices, data collection and transmission devices. The author analyzes the shortcomings of existing accounting and analysis automation systems at Russian water utilities. A comprehensive approach to automated systems in the field of water consumption accounting is proposed. The article considers the experience of the State unitary enterprise "Vodokanal of Saint Petersburg" in the sphere development and application of a single automated complex for diagnostics, monitoring and management of the water supply network. The goals and main functions of the complex are revealed, the main stages and results of its implementation are presented.
\end{abstract}

\section{Introduction}

As practice shows, the existing systems for automation of accounting and analysis at Russian water utilities are poorly integrated and are characterized by the following disadvantages:

- inability to ensure the quality and reliability of the source data;

- low level of automation, using routine technologies for data collection, transmission, storage and analysis;

- lack of means for tracking the status of measuring equipment;

- limited use of information about water consumption from subscribers' accounting systems for optimizing water supply;

- limited use of "standard" solutions;

- limited opportunities for predicting factors that affect the sustainability of water supply;

- lack of an automated approach to detecting unrecorded expenses (leaks, illegal connections, etc.);

- limited opportunities for operational management of the water supply system based on data obtained during measurements and analysis $[1,4,7]$.

As a result, there is an overspending of resources and significant water losses. For example, leaks and unrecorded water consumption, accounting only for officially recognized data $22.7 \%$ of all water supplied to the network. In practice, according to expert

* Corresponding author: serov da@me.com 
estimates, average water losses are at least $40 \%$. This situation definitely affects the financial position of resource-supplying organizations. The share of unprofitable water supply and sewerage enterprises is about $80 \%$.

In such conditions, the understanding that it would not be possible to reverse the existing negative trend relying only on the traditional methods is being actively formed. In this regard, the use of advanced information technologies will allow optimizing the activities of water supply companies and sewerage enterprises at a new level of quality [2, $3]$.

\section{Review of information technologies in water supply industry and justification of the need to introduce a new information technology in measuring the flow and volume of water}

The development of a system for measuring water flow and volume is an important element of the development Strategy of the state unitary enterprise "Vodokanal of Saint Petersburg". This project was launched due to the fact that the traditional system of measurements did not meet the requirements of scientific and technical progress in quality of customer service and efficiency of process water and efficient water use.

Therefore, the state unitary enterprise "Vodokanal of Saint Petersburg" is purposefully developing intelligent measurement systems. Firstly, such systems improve the quality of water supply services provided to the water subscribers. Secondly, they provide the result of measuring the flow rate and volume of water with the lowest error and with the highest accuracy. This allows you to calculate a reliable water balance and hydraulic model and on this basis actively identify and eliminate water losses, as well as encourage economical water consumption.

The development of intelligent measurement systems is ensured in the state unitary enterprise "Vodokanal of Saint Petersburg" by using modern technical means (flow meters) and implementing an automated system for collecting, storing and transmitting data on water consumption.

Primarily, there is a need for intelligent metering devices that can store data in nonvolatile memory. In addition, the smart device provides access to viewing the settings and characteristics of the device to track the parameters of its correct operation, the timing of the verification interval, and getting information about failures and malfunctions, and in real time.

Another element of the "smart measurement" system for water consumption is a data acquisition and transmission device that can collect data from any metering devices using standard open digital protocols using the technology of remote meter reading (Automatic Meter Reading, AMR). The various system architectures developed for remote reading can be divided into three broad categories: reading from a passing company employee, reading from a passing car, and network. In our experience, under the circumstances of building big cities with increasing traffic, and also for objects with a significant distance from the datacenters the networking technologies for taking data from remote meters become relevant.

Initially, the process of switching from manual reading to AMR systems was simply considered to be the way to reduce labor costs. However, as subscribers and service companies have become aware of the potential benefits of this technology, such as increased efficiency and reduced time interval during data collection, instant notification of failure detection and improved accuracy of readings, the ability to collect statistics on water consumption in the network, the value of AMR technology has increased significantly. 
The state unitary enterprise "Vodokanal of Saint Petersburg" currently considers it important to use a remote data transmission system based on the m-Bus Protocol (MeterBus).

The advantages of such system are as follows:

- minimum requirements for equipment and communication lines;

- easy to build, segment, and expand the network;

- speed of implementation and installation of necessary equipment;

- a large number of accounting points;

- length of communication lines up to several kilometers;

- high noise immunity;

- passive power supply source for slave devices;

- minimum costs for installation and operation of equipment.

\section{Creating an automated system for reducing water losses in water supply networks}

The state unitary enterprise "Vodokanal of Saint Petersburg" has created a unified automated system for diagnostics, monitoring and management of the water supply network based on promising solutions in the field of information systems and automation.

The main purposes for using this complex are as follows:

- sustainable and reliable water supply to water subscribers (customers);

- improving the manageability of the water supply system;

- identification of unrecorded expenses;

- reducing costs associated with the operation and maintenance of water infrastructure;

- transparent data generation for the system of payments with water subscribers.

An effective tool for achieving these goals is the automated system for accounting and analysis of water resources "Nemo Aqua" (rus. «Немо Аква»). This system combines the latest developments in various fields and uses the experience of the best Russian and foreign manufacturers. The project of development the water supply management system for "Vodokanal of St. Petersburg" has united hardware and software manufacturers, such as LLC “Alliance Electro", LLC “Siemens" (Germany), LLC "Meter”, JSC “Avangard”. JSC UK "Plant Vodopribor".

Main functions of the "NEMO Aqua" system are:

- rapid collection and analysis of reliable information from water service connection points (accounting nodes );

- building a balance of water consumption;

- forecasting of water consumption;

- identification and forecasting of emergency zones, objects, sections, and nodes;

- water flow control;

- providing data to end users.

The system includes intelligent metering devices, data collection, storage, and transmission equipment, as well as hardware and software parts.

The software package has three levels:

- the lower level includes objects equipped with a data transfer system to the middle level system (intersectoral flow meters, subscriber metering devices, pressure sensors, etc.);

- the middle level includes collecting and preparing data for the top-level system from related systems (EHD, is CRA, etc.) and transmitting data to the top-level system;

- the top level includes receiving, storing, and processing data, integrating with related systems, interacting with the user, tracking equipment operation, and tracking 
unrecorded water consumption.

The top-level system uses a hardware and software package developed on the basis of intelligent solutions that take into account the specifics of Russian water supply companies. Using Big Data technologies makes it easy to scale the solution to millions of subscribers $[5,6]$.

Thanks to using open, standard data transmission protocols the rapid and reliable collection of reliable information from the accounting nodes of the state unitary enterprise "Vodokanal of Saint Petersburg" is provided. The unique software package performs data processing and analysis in real time. At the same time, a powerful software package allows to collect and analyze a large amount of information (up to 20,000,000 accounting nodes). The hardware and software complex processes all the main and most of the secondary parameters of water supply, which are combined in the software modules, namely the modules: "Accounting and data management", "Analysis of the resource saving system", "Personal Analytics for the subscriber", "Data Preparation for billing".

At the same time, a single automated complex for water supply network diagnostics, monitoring and management organically covers the most important components of the water utility's technological infrastructure (see Fig. 1).

\section{Characteristics of the stages of the automated complex for diagnostics, monitoring and management of the water supply network development}

The development and implementation of a single automated system for diagnostics, monitoring and management of the water supply network was implemented at "Vodokanal in Saint Petersburg" in several stages.

The first stage is associated with the allocation of hydraulically isolated sections (sectors) in the distribution network, where water consumption is controlled by water meters:

- water consumption accounting;

- leak detection;

- pressure control.

The following principles can be used to identify water supply sectors: boundaries of administrative districts, elevation differences, number of flows, and location of crossindustry flow meters. 




Fig. 1. Automated diagnostics, monitoring and management of the water supply network in the technological infrastructure of the water utility.

The second stage is the inventory of water supply system objects and updating the state of the shut-off valves for hydraulic isolation of the selected sectors.

The third stage is the selection of "key" points.

At this stage, it is necessary to determine the optimal number of automated water metering units (key points) on subscriber lines/highways, based on the readings of which it is possible to assess the picture of water consumption in the entire water supply sector.

The choice was made on the basis of mathematical analysis and optimal selection of objects that most fully describe the state of the consumption area and characteristic consumers, taking into account the topology of the water supply network, the consumption of subscribers and minimizing the cost of implementing the project

The fourth stage is the equipment of key points.

Each key point is equipped with a water consumption measurement device, a pressure sensor, and a data collection, storage, and transmission device.

The fifth stage is the alignment of business processes.

The sixth stage is integration and synchronization of top-level systems (data collection and transmission server, unified data storage, Energy IP platform, Analytics and reports, adapters, personal account, administrator, operator, user and consumer interfaces, etc.).

The seventh stage is the implementation and evaluation of the effectiveness of a single automated system for diagnostics, monitoring and management of the water supply network. 


\section{Results: information technologies implementation for water accounting in the state unitary enterprise "Vodokanal of Saint Peterburg"}

The use of modern technologies for measuring and recording water consumption can significantly improve the quality of customer service [11]. Thus, consumers of services without additional costs receive a number of advantages provided by the "User's Personal account" and related primarily to the analysis of water consumption and rationality of its use:

- with the help of automatically generated graphs and charts, the subscriber can see water consumption on a monthly basis, depending on the time of day, season, display consumption in natural and monetary values, with the ability to build graphs, forecasts of consumption and analysis of results;

- one can compare his own costs with the average for the city/district/home;

- it is possible to analyze and control water consumption for General household needs, get recommendations for economical use of water, get acquainted with pricing options in the case of variable tariffs;

- provides for automatic notification when certain events occur (overspending, leakage or malfunction of the device), information about which the system will send it by e-mail or SMS;

- provides the ability to set thresholds for informing water subscribers (for example, approaching a certain consumption limit, overspending);

Eventually, the process of water consumption becomes manageable, and managed in a timely manner.

In turn, the resource-supplying organization, when implementing an automated system for collecting, storing and transmitting data on water consumption, also receives significant benefits:

- reliability of measurements and accounting for consumers allows for transparency in the calculations between the consumer and the service provider, as well as stimulate the consumer's choice of an economical mode of water consumption;

- monitoring of unrecorded water consumption and losses, forecasting water consumption, identifying discrepancies in the statistics of instrumentation readings, analyzing the causes and localizing the places where they occur allow the subscribers to use water economically;

- storage of measurement data in the device's non-volatile memory allows to make validation and verification of transmitted and received data;

- open data collection protocols allow to use metering devices from any manufacturer;

- based on data processing, it becomes possible to generate summary analytical reports and build graphs based on customer requests, such as displaying consumption in physical and monetary terms, statistics and forecast of consumption, and results of environmental impact;

- water consumption balance formation allows to detect places of water leaking faster;

- there is no need to take and transmit water meter readings manually every month, it becomes possible to collect readings without participation of houses' residents, users of the water supply system, and additional personnel of the state unitary enterprise "Vodokanal of Saint Petersburg".

- providing flexibility and scalability of the system (currently up to 20 million water subscribers).

It is possible to receive data from water counters in various ways (for example, using a mobile phone, tablet, or personal computer). 
The experience accumulated in the state unitary enterprise "Vodokanal of Saint Petersburg" shows that it is necessary to move from separate isolated actions of resourcesupplying organizations to integration of efforts. For example, in many cases it is already necessary to combine data on the consumption of heat, water, gas and electricity into a single database. This simplifies greatly the work of responsible persons in such organizations. It is also very important to ensure the technical and software compatibility of new or upgraded measuring instruments.

Finally, the construction of large-scale automated systems, especially such important ones as systems for accounting of the various utility resources' consumption, is associated with organizational and technical difficulties that cannot be solved without a reasonable unification of the applied technical solutions $[12,15]$.

In this regard, there are two problems that need to be solved in the future:

- automation requires converting data about resource consumption to digital format (for further transmission, processing and storage), but in accordance with current legislation subscribers have the right to install "non-intelligent" water counters that do not output data in the required format or do not provide the storage of data [11];

- most manufacturers of modern "smart" meters use their own data exchange protocols and their own software for data registration and analysis [12]. As a result, when implementing any complex project associated with the automation of data collection, interfaces from different manufacturers cannot work in the same communication environment, with the same driver or communication server. Therefore, there is a need for additional communication modules or software. It certainly makes creating of a system for collecting, storing, transmitting, and analyzing data much more difficult, and increases its cost [13].

To solve these problems, it is important to unify data transmission in such a way that it is possible to automatically take readings from metering devices of any manufacturer and transmit data to the information systems of different resource-supplying organizations in any digital format they need $[13,14]$. It means that the system should be built on the basis of a unified communication Protocol.

In General, modern technologies for measuring and recording the consumption of municipal resources reflect the objective requirements of scientific and technological progress. Such technologies are designed to make a significant contribution to improving the efficiency of resource-supplying organizations and the quality of services provided.

\section{Conclusion}

By 2018, with the introduction of the system in "Vodokanal of Saint Petersburg", electricity consumption has been reduced by $21 \%$, water losses have been reduced by $22 \%$, and pipe damage has been reduced by $44 \%$. At the same time, it is important to understand that building of an automated measurement system would not be effective if the only purpose of a system is to solve billing problems. The greatest effect is achieved when building a water balance system for monitoring and analyzing water leaks.

In General, the introduction of the "Nemo Aqua" automated water resource accounting and analysis system increases the stability and reliability of water supply system and water supply management, reduces the cost of operating and maintaining the water supply infrastructure, and provides transparent data generation for the system of payments to water subscribers. Thus, the quality of water supply is steadily improving.

In our opinion, further development of the "Nemo Aqua" automated accounting and analysis system is possible in the following main areas:

- developing the functionality of the automated system itself and simplifying its operation; 
- replication of the automated system (implementation at other enterprises of water supply and water disposal);

- use of automated systems' elements in management other utilities (gas, heat and power supply).

\section{References}

1. I.V., Karnatsevich, G.G. Bikbulatova, and K.V. Ryapolov, Omsk scientific Bulletin, Series 1 «The Resources Of The Earth. The Human» 1(104), 224-231 (2011)

2. Krasnoyarsk economic forum (2017) http://www.aetp.ru/news/item/410261

3. T.S. Nagornaya, Young scientist 20, 260-262 (2017) DOI: https://moluch.ru/archive/154/43556

4. A.E. Saak, E.V. Pahomov, and V.N. Tyushnyakov, Information technologies management: Textbook for universities (2nd edn.,"Piter" Publishing House, Saint Petersburg, 2012)

5. A.R. Saitgaraev, G.A. Gareeva, and D.R. Grigor'eva, Young scientist 28, 526-529 (2016) DOI: https://moluch.ru/archive/132/36970

6. Digitalization in the field of housing and communal services, DOI : https://www.osp.ru/cw/2017/10/13052377

7. Digital housing and communal services: is it easy to implement the President's plans? DOI: $\quad$ http://www.iksmedia.ru/blogs/post/5398071-Czifrovoe-ZHKX-legko-lirealizovat.html

8. D.V. Gorbachev, E.G. Hakimova, Young scientist 13, 33-35 (2015) DOI: https://moluch.ru/archive/93/20566

9. Innovations and new technologies in the field of housing and communal services, DOI: https://www.rc-online.ru/about/smi/innovatsii-i-novye-tekhnologii-v-sfere-zhkkh

10. A.N. Pavlov, Proc. of the 6th Intern. Scientif. Conf. "Problems and prospects of economy and management, 222-225 (2017) DOI: https://moluch.ru/conf/econ/archive/263/13269

11. A.E. Parshkov, Technic. Technologies. Engineering 1, 14-17 (2018) DOI: https://moluch.ru/th/8/archive/76/3012

12. V.V. Chaadaeva, New science: Strategies and vectors of development 3-1 (70), 250 (2016)

13. A.S. Makarov, M.V. Bolsunovskaya, et al., ETU "LETI", 61-64 (2018)

14. V.N. Volkova, A.A. Denisov, Systems theory and systems analysis: textbook (2nd edn.,URAIT Publishing House, Moscow, 2017)

15. M.V. Bolsunovskaya, S.V. Shirokova, et al., 2nd International Scientific Conference on Digital Transformation on Manufacturing, Infrastructure and Service, St. Petersburg (2018) DOI: 10.1088/1757-899X/497/1/012024 